\title{
Different Smoking Statuses on Survival and Emphysema in Patients with Acute Exacerbation of Chronic Obstructive Pulmonary Disease
}

\author{
Qi Ding $\mathbb{D}^{1, *}$, Jie Li $\mathbb{D}^{1, *}$, Shudi Xu $\mathbb{D}^{1}$, Yanzhong Gao $\mathbb{D}^{2}$, Youmin Guo $\mathbb{D}^{3}$, Baozhu Xie $\mathbb{D}^{1,4}$, \\ Hua Li (D) ${ }^{\prime, 4}$, Xia Wei (D) \\ 'Department of Pulmonary and Critical Care Medicine, The Ninth Hospital of Xi'an Affiliated with Xi'an Jiaotong University, Xi'an, Shaanxi; \\ ${ }^{2}$ Department of Radiology, The Ninth Hospital of Xi'an affiliated with Xi'an Jiaotong University, Xi'an, Shaanxi; ${ }^{3}$ Department of Radiology, The First \\ Affiliated Hospital of Xi'an Jiaotong University, Xi'an, Shaanxi; ${ }^{4}$ The Medical School of Yan'an University, Yan'an, Shaanxi \\ *These authors contributed equally to this work
}

Correspondence: Xia Wei, Department of Pulmonary and Critical Care Medicine, The Ninth Hospital of Xi'an affiliated with Xi'an Jiaotong University, Xi'an, Shaanxi, Tel +18891991910, Email wx2005hope@I26.com

Objective: To investigate the association between different smoking statuses and survival and emphysema in patients with acute exacerbation of chronic obstructive pulmonary disease (AECOPD).

Methods: This retrospective study included patients admitted from October 2014 to September 2017. Demographic, clinical, laboratory, imaging, impulse oscillometry, and traditional pulmonary function data were collected. The relationship between smoking and EI was analyzed via binary logistic regression after adjusting for other factors. Survival was analyzed using the Kaplan-Meier method and the log rank test.

Results: The patients with AECOPD (357 cases) were identified (and stratified into three groups: never smoked (NS; n=83), former smokers (FS, $n=118$ ), and current smokers (CS; $n=156)$. Compared with CS, NS were older and predominantly female. No differences were observed in respiratory symptoms and acute exacerbation between CS and NS. NS had higher resistance and reaction in the central and peripheral airways, while CS exhibited more severe diffuse dysfunction. CS demonstrated more severe and extensive emphysema. Smoking was an independent risk factor for emphysema after adjusting for age, forced expiratory volume in the first second over predicted value, BMI, leukocyte count, and carbon monoxide transfer coefficient. No difference in 5-year survival rates between NS and CS was established.

Conclusion: CS has the worst pulmonary function, suggesting a more important destruction of the lung parenchyma, while AECOPD without smoking risk factors mostly affects the airways. Impulse oscillometry can be used for imaging airway-dominant AECOPD. There was no difference in the 5-year survival rate.

Keywords: chronic obstructive pulmonary disease, acute exacerbation, smoking, impulse oscillometry system, emphysema index

\section{Introduction}

Chronic obstructive pulmonary disease (COPD) is projected to be the third leading cause of death worldwide, ${ }^{1}$ with the health impact and economic cost of COPD posing a dual burden to society. ${ }^{2}$ COPD is a complex chronic inflammatory disease involving central airways, small airways, lung tissue, and pulmonary vessels, ${ }^{3}$ presenting heterogeneous characteristics.

COPD is associated with a variety of risk factors (the main one being smoking, but also including genetic factors, family history of COPD, indoor/outdoor air pollution, inflammatory conditions, infections, medications, diet, and snoring $)^{3,4}$ though more than $20 \%$ of COPD patients have never smoked. ${ }^{5}$ The same factors are also associated with response to treatment and prognosis. ${ }^{3,4}$ There are specific etiological characteristics and risk factors for COPD in China, including an estimated 312 million Chinese who are smoking. ${ }^{6}$ Previous studies showed that cigarette smoking 
and second-hand smoking are important risk factors for $\mathrm{COPD} .{ }^{7,8}$ Other risk factors include biofuel combustion, ambient air pollution, underweight, childhood chronic cough, and parental history of respiratory diseases. ${ }^{7}$ It is unclear, however, whether different risk factors result in different clinical and pathological features. Furthermore, it is unknown whether COPD caused by different pathogenic risk factors has different prognostic outcomes and these issues deserve more exploration.

Patients having an acute exacerbation of COPD (AECOPD) have a 5-year survival of 50\% after hospitalization for exacerbation. ${ }^{3}$ Treatment of AECOPD requires different treatment modalities and vast medical resources. Although many studies addressed stable COPD, data about AECOPD is scarcer. While clinical and laboratory investigations, pulmonary function tests, and computed tomography (CT) can reveal some characteristics, no single modality can adequately represent the disease's full spectrum. The COPDGene study assessed the patients in a multidimensional fashion to enhance the understanding of the complex structural and functional changes in COPD. ${ }^{9}$ In previous studies by the authors' group, ${ }^{10-13}$ the parameters mentioned above were combined to uncover the characteristics of the AECOPD population.

Still, the impact of different lifetime smoking statuses on AECOPD requires investigation. Therefore, this study aimed to investigate the differences in clinical features, inflammatory markers, lung function indicators, imaging parameters, and survival of AECOPD in current smokers (CS), former smokers (FS), and never smokers (NS) and also attempted to identify the characteristic changes of AECOPD associated with smoking.

\section{Methods}

\section{Study Design and Patients}

This retrospective study included patients admitted to the Department of Respiratory Medicine at the authors' hospital from October 2014 to September 2017. This work has been carried out in accordance with the Declaration of Helsinki (2000) of the World Medical Association. This study was approved by the ethics committee of Xi'an ninth hospital (\#014001). The data used in the study did not involve information that can be used to identify the patients. The use of the patient data will not adversely affect patients. All data were collected from the medical charts. No new tests or measurements were performed. The patients were not contacted to obtain new data. Therefore, due to the retrospective nature of this study, informed consent of patients was waived.

The inclusion criterion was patients diagnosed with AECOPD according to the Global Initiative for Obstructive Lung Disease (GOLD) diagnostic criteria (forced expiratory volume at 1 second/forced vital capacity, FEV1/FVC $<70 \%$ after inhalation of a bronchodilator). ${ }^{3}$ The exclusion criteria included 1) $<40$ years of age, 2) pregnancy, 3) comorbid lung diseases including lung cancer, pneumonia, active pulmonary tuberculosis, pulmonary embolism, or interstitial lung disease, 4) previous lung surgery, 5) inability to complete the pulmonary function test (PFT), 6) asthma or severe heart, liver, or kidney dysfunction, or 7) high-resolution computed tomography (CT) quality insufficient for analysis.

\section{Data Collection}

The electronic medical records were accessed to collect all data variables, including demographics (sex, age, and smoking status), body mass index (BMI), the number of hospitalizations due to AECOPD over the past 12 months, inflammatory indicators, including white blood cell count (WBC), neutrophil ratio (N\%), eosinophil ratio (E\%), fibrinogen(FIB), C-reactive protein (CRP), procalcitonin (PCT), arterial oxygen partial pressure $\left(\mathrm{PaO}_{2}\right)$, arterial carbon dioxide partial pressure ( $\mathrm{PaCO} 2)$, and comorbidities, including coronary heart disease, hypertension, and diabetes. The routinely administered self-report questionnaires of the COPD Assessment Test (CAT) and Modified Medical Research Council Dyspnea Index (mMRC) were collected from the medical charts. ${ }^{10,13}$

Other collected variables were the ratio of forced expiratory volume occupancy in the first second (FEV1/FVC), the ratio of forced expiratory volume in 1 second to predicted (FEV1\%pred), the ratio of carbon monoxide diffusion to alveolar ventilation (KCO), the ratio of residual volume to total lung volume (RV/TLC), and the ratio of maximal midexpiratory flow to predicted $\left(\mathrm{MMEF}_{25-75 \% \mathrm{pred}}\right)$. The total respiratory impedance $\left(\mathrm{Z}_{5}\right)$, resistance at $5 \mathrm{~Hz}\left(\mathrm{R}_{5}\right)$, resistance at $20 \mathrm{~Hz}\left(\mathrm{R}_{20}\right)$, resistance at $5 \mathrm{~Hz}-$ resistance at $20 \mathrm{~Hz}\left(\mathrm{R}_{5}-\mathrm{R}_{20}\right)$, reactance at $5 \mathrm{~Hz}\left(\mathrm{X}_{5}\right)$, resonant frequency (Fres), and 
reactance area $(\mathrm{Ax})$ detected in patients without wheezing symptoms by spirometry and the impulse oscillometry system (IOS) (Master Screen IOS, Erich Jaeger, Hochberg, Germany) were collected. ${ }^{12,13}$

Patients with AECOPD with available imaging data included 65 NS, 83 FS, and 115 CS. The CT imaging parameters assessed included the percentage of the wall area (\%WA), emphysema, mean emphysema density (MED), mean lung density (MLD), lung capacity (LC), and emphysema heterogeneity index (HI) of the whole lung, right lung, and left lung detected by 64-detector CT (SOMATOM Definition AS, Siemens HealthCare, Germany) and analyzed using an in-house system (FACT-Digital Lung) ${ }^{14}$ and collected as described previously. ${ }^{10,13}$ The primary outcome of this study was the 5-year survival rate. Patients were followed up until April 2021. For patients lost to follow-up, the vital status was obtained from the government.

\section{Definitions}

NS was defined as a lifetime exposure of $<1$ cigarette/year. ${ }^{15}$ FS was defined who had quit smoking for more than 1 year. CS was defined as individuals who still smoked. The \%WA and lung volume with a CT attenuation value below $-950 \mathrm{HU}$ (\%LAA-950) was defined as the emphysema index (EI). Emphysema (\%LAA), mean emphysema density (MED), mean lung density (MLD), lung capacity (LC), and emphysema heterogeneity index (HI) were recorded for the whole lung (HI whole lung), right lung ( $\mathrm{HI}$ right lung), and left lung ( $\mathrm{HI}_{\text {left lung }}$ ). The \%WA distribution of the bronchus of different generations in each lung lobe was expressed as $\% \mathrm{WA}_{\mathrm{RUL4}-7}, \% \mathrm{WA}_{\mathrm{RML} 4-7}, \% \mathrm{WA}_{\mathrm{RLL} 4-9}, \% \mathrm{WA}_{\text {LUL4-7 }}$, and \%WA $\mathrm{WLL}_{4-9}$.

\section{Statistical Analysis}

All analyses were performed using SPSS 19.0 (IBM Corporation, Armonk, NY, USA). The Kolmogorov-Smirnov test was used to assess whether the data conformed to the normal distribution. Continuous data conforming to the normal distribution were displayed as mean \pm standard deviation; data not conforming to the normal distribution were displayed as median (IQR). If the continuous data were normally distributed and the variances were uniform, a one-way analysis of variance was used. The Bonferroni test provided a further pairwise comparison between groups. For continuous data not normally distributed, the Kruskal-Wallis test was used to evaluate the differences among the three groups and for comparison between every two groups with a $p$-value of 0.016. $p<0.05$ was considered significant elsewhere. Categorical variables were displayed in $\mathrm{n}(\%)$ and analyzed by chi-square test. The relationship between smoking and EI was analyzed via binary logistic regression after adjusting for other factors, with a probability value for entry $(p=0.1)$ and removal $(p=0.05)$. Correlation analysis between the amount of smoking and EI was done with the Spearman test. Survival curves for the two main groups (never smokers and all smokers) were constructed according to the KaplanMeier method and compared using the log rank test.

\section{Results}

\section{Comparison of Demographic and Clinical Data}

Age and sex-related differences were observed between the NS and smoker (both FS and CS) groups. NS were older, with a greater preponderance of females. Further comparison of the three groups revealed that the age of the NS and FS groups was higher than that of the CS group $(p<0.001)$. The percentage of males in the NS group was lower than in the FS and CS groups $(p<0.001)$. The mMRC of the FS group was higher than in the CS group $(p<0.001)$. No significant differences were observed in BMI, CAT, N\%, E\%, platelet, FIB, CRP, PCT, $\mathrm{PaO}_{2}$, and $\mathrm{PaCO}_{2}$ (Table 1).

\section{Comparison of PFTs}

Differences were observed between the results of traditional PFTs (ie, FEV1/FVC and $\mathrm{DL}_{\mathrm{CO}} / \mathrm{VA}$ ) of the NS and smoker (including $\mathrm{FS}$ and $\mathrm{CS}$ ) groups. NS exhibited higher $\mathrm{FEV1/FVC}$ and $\mathrm{DL}_{\mathrm{CO}} / \mathrm{VA}$ than all smokers. There were no differences between $\mathrm{FEV} 1 / \mathrm{FVC}$ and $\mathrm{DL}_{\mathrm{CO}} / \mathrm{VA}$ in the $\mathrm{FS}$ and CS groups. No significant differences were found in FEV1\% $\%_{\text {pred }}, \mathrm{MMEF}_{25-75 \%}$, and RV/TLC among the three groups (Table 2, Figure 1A). 
Table I Demographic and Baseline Characteristics

\begin{tabular}{|c|c|c|c|c|}
\hline Characteristics & $\begin{array}{l}\text { Never Smokers } \\
(n=83)\end{array}$ & $\begin{array}{l}\text { Former Smokers } \\
(n=|| 8)\end{array}$ & $\begin{array}{l}\text { Current Smokers } \\
(n=\mid 56)\end{array}$ & $P$-value \\
\hline $\begin{array}{l}\text { Age, years } \\
\text { Gender }\end{array}$ & 7I (64 79) & 71.5 (65 79) & $63.5(58 \sim 70) * \#$ & $<0.001$ \\
\hline Male (\%) & 49 (59\%) & $114(96.6 \%) *$ & $153(98.1 \%) *$ & $<0.001$ \\
\hline Female (\%) & 34 (4I\%) & $4(3.4 \%) *$ & $3(1.9 \%) *$ & $<0.001$ \\
\hline Comorbidities & I (0 2) & I (0 2) & I $(0 \sim 1)$ & 0.238 \\
\hline Exacerbations/year & $0(0 \sim 1)$ & $0(0 \sim 2)$ & $0(0 \sim 1)$ & 0.049 \\
\hline CAT & $19(14 \sim 26.5)$ & $19(14 \sim 25)$ & $20.5(12 \sim 25)$ & 0.712 \\
\hline $\mathrm{mMRC}$ & $\mathrm{I}(0 \sim 2)$ & $2(1 \sim 3)$ & I (0 2) ${ }^{\#}$ & 0.002 \\
\hline BMI $\left(\mathrm{kg} / \mathrm{m}^{2}\right)$ & $23.5 \pm 3.9$ & $22.8 \pm 3.6$ & $23.1 \pm 3.9$ & 0.448 \\
\hline WBC, $\left(\times 10^{9} / \mathrm{L}\right)$ & $6.5(5.02 \sim 7.79)$ & 6.84 (5.47 9.38) & $6.84(5.31 \sim 8.68)$ & 0.091 \\
\hline Neutrophils, (\%) & $71.21 \pm 12.07$ & $73.25 \pm 11.19$ & $70.35 \pm 11.9$ & 0.124 \\
\hline Lymphocytes, (\%) & $21.3(13.25 \sim 27.1)$ & $18.85(10.8 \sim 23.9)$ & $20.6(14.2 \sim 27.65)$ & 0.11 \\
\hline Eosinophils, (\%) & $1.4(0.4 \sim 2.9)$ & $1.5(0.5 \sim 3.3)$ & $1.55(0.35 \sim 3)$ & 0.813 \\
\hline PLT, $\left(\times 10^{9} / \mathrm{L}\right)$ & 163 (I31.5 209.5) & $161.5(124 \sim 227)$ & $167.5(134 \sim 212)$ & 0.977 \\
\hline FIB $(g / L)$ & $3.93(3.26 \sim 5.16)$ & $3.84(3.19 \sim 5.07)$ & $3.95(3.13 \sim 4.81)$ & 0.829 \\
\hline D-Dimer(ug/ml) & $0.91(0.61 \sim 1.28)$ & $0.9(0.67 \sim 1.46)$ & $0.9(0.66 \sim 1.28)$ & 0.963 \\
\hline CRP (mg/L) & $6.99(3.28 \sim 23.15)$ & $9.64(3.28 \sim 38.2)$ & $6(3.28 \sim 24.8)$ & 0.164 \\
\hline PCT(ng/ml) & $0.05(0.05 \sim 0.05)$ & $0.05(0.05 \sim 0.05)$ & $0.05(0.05 \sim 0.05)$ & 0.475 \\
\hline $\mathrm{PH}$ & 7.42 (7.4 7.44) & 7.42 (7.39 7.44) & 7.41 (7.38 7.44) & 0.067 \\
\hline $\mathrm{PaO}_{2}(\mathrm{mmHg})$ & 78 (67.5 89) & 73 (65 88) & $73(64 \sim 83)$ & 0.123 \\
\hline $\mathrm{PaCO}_{2}(\mathrm{mmHg})$ & $40(36 \sim 44)$ & $42(38 \sim 47)$ & $42(37 \sim 48)$ & 0.074 \\
\hline
\end{tabular}

Notes: ${ }^{*} P<0.05$ compared with NS; ${ }^{\#} P<0.05$ compared with FS.

Abbreviations: BMI, body mass index; GOLD, Global Initiative for Chronic Obstructive Lung Disease; COPD, chronic obstructive pulmonary disease; WBC, white blood cell count; N, neutrophil; E, eosinophils; PLT, blood platelet count; FIB, fibrinogen; CRP, C-reactive protein; PCT, procalcitonin; PaO ${ }_{2}$, arterial oxygen partial pressure; $\mathrm{PaCO}_{2}$, arterial carbon dioxide partial pressure.

Table 2 PFT Parameters

\begin{tabular}{|c|c|c|c|c|}
\hline Parameters & $\begin{array}{l}\text { Never Smokers } \\
n=83\end{array}$ & $\begin{array}{l}\text { Former Smokers } \\
n=118\end{array}$ & $\begin{array}{l}\text { Current Smokers } \\
n=156\end{array}$ & $P$-value \\
\hline FEVI (L) & $1.14(0.77 \sim 1.56)$ & I. 18 (0.84 1.59) & $1.37(0.95 \sim 1.77) * \#$ & 0.005 \\
\hline FEVI\% ${ }_{\text {pred }}$ & $49.6(37 \sim 66.35)$ & 45.75 (31.2 57) & $45.4(35.6 \sim 58.4)$ & 0.089 \\
\hline $\mathrm{FVC}_{\% \text { pred }}$ & $70.2(55.5 \sim 86.3)$ & $68.3(51.8 \sim 79.5)$ & $67.05(56.4 \sim 79.9)$ & 0.376 \\
\hline FEVI/FVC (\%) & $58.78(48.63 \sim 63.74)$ & $52.38(44.23 \sim 60.27) *$ & $53.68(45.07 \sim 60.32) *$ & 0.007 \\
\hline PEF \% $\%_{\text {pred }}$ & $39.2(28.25 \sim 5 \mid .2)$ & $37.5(28 \sim 46.1)$ & $39(29.85 \sim 48.8)$ & 0.599 \\
\hline $\mathrm{MMEF}_{25-75 \%}$ & 19.4 (14 28.9) & $18.6(12.8 \sim 25)$ & 19.25 (I3.7 27) & 0.598 \\
\hline DL $L_{C O} / V A(\%)$ & $89.5 \pm 22.27$ & $78.29 \pm 25.86 *$ & $75.63 \pm 23.98^{*}$ & $<0.001$ \\
\hline RV/TLC (\%) & $57.09 \pm 10.48$ & $58.44 \pm 11.2$ & $55.14 \pm 10.84$ & 0.051 \\
\hline Z5\%pred & I82.| (|44.5 219.6) & I 75.6 (| $43 . \mid$ | 207.4) & $169.6(142.8 \sim 205.8)$ & 0.483 \\
\hline $\mathrm{R}_{5}(\mathrm{kPa} / \mathrm{L} / \mathrm{s})$ & $0.58(0.48 \sim 0.67)$ & $0.49(0.42 \sim 0.58) *$ & $0.47(0.39 \sim 0.56) *$ & $<0.001$ \\
\hline $\mathrm{R}_{20}(\mathrm{kPa} / \mathrm{L} / \mathrm{s})$ & $0.36(0.32 \sim 0.42)$ & $0.32(0.28 \sim 0.36) *$ & $0.32(0.29 \sim 0.37) *$ & $<0.001$ \\
\hline $\mathrm{R}_{5}-\mathrm{R}_{20}(\mathrm{kPa} / \mathrm{L} / \mathrm{s})$ & $0.21(0.12 \sim 0.28)$ & $0.16(0.11 \sim 0.22)$ & $0.14(0.09 \sim 0.2) *$ & 0.001 \\
\hline$X_{5}$ & $-0.26(-0.38 \sim-0.17)$ & $-0.22(-0.32 \sim-0.14)$ & $-0.2(-0.29 \sim-0.14) *$ & 0.009 \\
\hline Fres $(\mathrm{Hz})$ & $23.34 \pm 5.79$ & $22.73 \pm 5.07$ & $21 \pm 5.23^{* \#}$ & 0.002 \\
\hline $\mathrm{Ax}(\mathrm{kPa} / \mathrm{L})$ & $2.18(1.27 \sim 3.09)$ & 1.88 (I.06 2.57) & $1.49(0.89 \sim 2.36) *$ & 0.003 \\
\hline
\end{tabular}

Notes: $* P<0.05$ compared with NS group; ${ }^{\#} P<0.05$ compared with FS group.

Abbreviations: PFT pulmonary function test, FEVI forced expiratory volume in I second, FVC forced vital capacity, FEVI/FVC forced expiratory volume in I sec/forced vital capacity, $\mathrm{MMEF}_{25-75 \%}$ maximal mid expiratory flow, RV/TLC residual volume/total lung capacity, $\mathrm{DL}_{\mathrm{CO}} / \mathrm{VA}$ ratio of carbon monoxide diffusion capacity to alveolar ventilation, \%Pred, of the predicted value, $\mathrm{Z} 5$ total respiratory impedance, $\mathrm{R}_{5}$ resistance at $5 \mathrm{~Hz}, \mathrm{R}_{20}$ resistance at $20 \mathrm{~Hz}, \mathrm{X}_{5}$ reactance at $5 \mathrm{~Hz}$, Fres response frequency, $\mathrm{Ax}$ reactance area. 

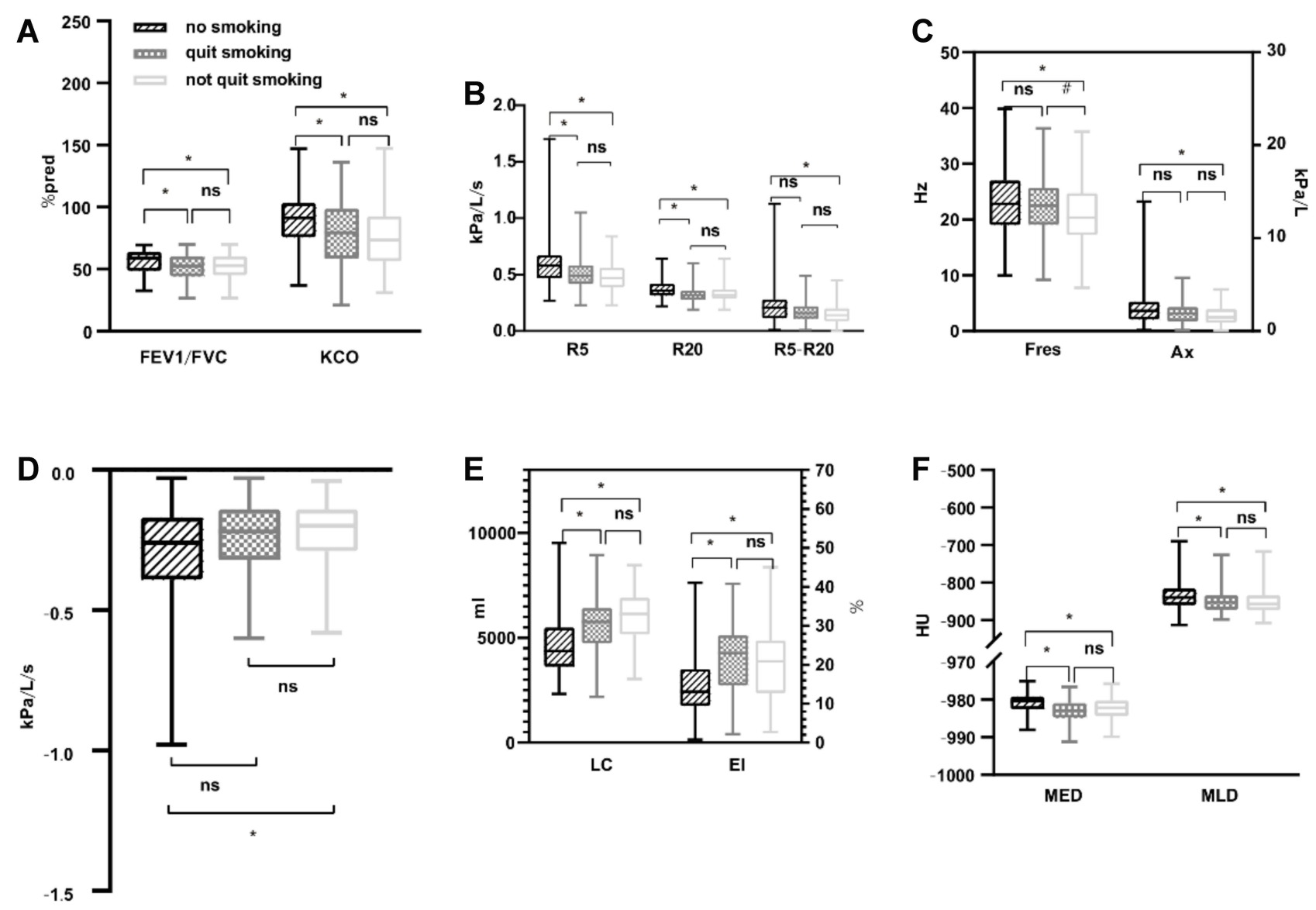

Figure I Comparison of two lung function test parameters and imaging parameters. (A) Comparison of FEVI/FVC and DL $L_{C o} / V C$. (B) Comparison of $R_{5}, R_{20}, R_{5}-R_{20}$. (C) Comparison of Fres and Ax. (D) Comparison of $X_{5}$. (E) Comparison of LC and El of whole lungs. (F) Comparison of MED and MLD of whole lungs. Notes: $* P<0.05$ compared with NS (no smoking); ${ }^{\#} P<0.05$ compared with FS (quit smoking).

Abbreviation: $\mathrm{FEVI} / \mathrm{FVC}$ the ratio of forced expiratory volume occupancy in the first second, $\mathrm{KCO}$ the ratio of carbon monoxide diffusion to alveolar ventilation, $R_{5}$ resistance at $5 \mathrm{~Hz}, R_{20}$ resistance at $20 \mathrm{~Hz}, R_{5}-R_{20}$ resistance at $5 \mathrm{~Hz}$-resistance at $20 \mathrm{~Hz}, X_{5}$ reactance at $5 \mathrm{~Hz}$, Fres resonant frequency, $A_{X}$ reactance area, El emphysema index, MED mean emphysema density, MLD mean lung density, LC lung capacity, NS, no significance.

The resistance at $\mathrm{R}_{5}, \mathrm{R}_{20}, \mathrm{R}_{5}-\mathrm{R}_{20}, \mathrm{X}_{5}$, Fres, and Ax on the IOS test differed between the NS and smokers (former and current smokers) groups (Table 2, Figure 1B-D). NS with AECOPD had a higher resistance and reactance in the central airway and lung periphery compared with smokers with AECOPD, particularly with CS.

\section{Comparison of CT Imaging Features Among the Three Groups}

The LC $\mathrm{L}_{\text {whole lung, }} \mathrm{LC}_{\text {Right lung, and LC }}$ Left lung of smokers (including FS and CS) was higher than in NS ( $\left.p<0.001\right)$ (Table 3), but these parameters did not differ between FS and CS (Figure 1E).

The EI and MED reflect the extent and severity of emphysema. The MLD reflects overall lung parenchymal damage. The EI, MED, and MLD of smokers (both former and current) exhibited more critical changes than those of NS in the whole lung, right lung, and left lung $(p<0.001)$ (Table 3). However, there were no differences between FS and CS (Figures 1E, F and 2).

There were no significant differences between the $\mathrm{HI}_{\text {whole lung, }} \mathrm{HI}_{\text {Right lung, and } \mathrm{HI}}$ Left lung $(\mathrm{HI}$ represents emphysema distribution) of never smokers and smokers (including former and current smokers; $p>0.016$ ) (Table 3). There were no significant differences in the $\% \mathrm{WA}_{\mathrm{RUL} 4-7}, \% \mathrm{WA}_{\mathrm{RML} 4-7}, \% \mathrm{WA}_{\mathrm{RLL} 4-9}, \% \mathrm{WA}_{\mathrm{LUL} 4-7}$, and $\% \mathrm{WA}_{\mathrm{LLL} 4-9}$ between the three groups $(p>0.05)$ (Supplementary Table S1). 
Table 3 Imaging Characteristics

\begin{tabular}{|c|c|c|c|c|}
\hline Parameters & $\begin{array}{l}\text { Never Smokers } \\
n=65\end{array}$ & $\begin{array}{l}\text { Former Smokers } \\
n=83\end{array}$ & $\begin{array}{l}\text { Current Smokers } \\
n=1 \mid 5\end{array}$ & $P$-value \\
\hline LC Whole $(\mathrm{ml})$ & $4594.28 \pm 1332.85$ & $5663.81 \pm 1305.35^{*}$ & $6004.53 \pm 1252.95^{*}$ & $<0.001$ \\
\hline LC Right lung $(\mathrm{ml})$ & $2495.24 \pm 7 \mid 2.45$ & $3033.31 \pm 700.95^{*}$ & $3201.49 \pm 655.4^{*}$ & $<0.001$ \\
\hline LC Left lung $(\mathrm{ml})$ & $2099.03 \pm 643.76$ & $2630.5 \pm 644.48^{*}$ & $2824.56 \pm 605.5^{*}$ & $<0.001$ \\
\hline \%LAA_950 Whole lung & $14.94 \pm 7.93$ & $21.45 \pm 9.25 *$ & $20.54 \pm 9.5^{*}$ & $<0.001$ \\
\hline \%LAA_950 Right lung & $13.89(9.26 \sim 18.75)$ & $21.93(15.17 \sim 28.45) *$ & $20.73(13.53 \sim 26.48) *$ & $<0.001$ \\
\hline \%LAA-950 Left lung & I3.67 (8.96 19.85) & $22.11(14.33 \sim 27.57) *$ & $21.35(12.29 \sim 26.83) *$ & $<0.001$ \\
\hline MED Whole lung $(H U)$ & $-980.44(-982.54 \sim-979.23)$ & $-983(-984.8 \sim-981.15) *$ & $-982.23(-984.3 \sim-980.35) *$ & $<0.001$ \\
\hline MED Right lung $(H U)$ & $-980.06(-982.64 \sim-978.72)$ & $-982.84(-984.7 \mid \sim-980.875) *$ & $-981.69(-984.24 \sim-980.07) *$ & $<0.001$ \\
\hline MED Left lung $(H U)$ & $-980.78(-982.94 \sim-979.9)$ & $-983.3(-984.74 \sim-981.2) *$ & $-982.6(-984.79 \sim-980.21) *$ & 0.001 \\
\hline MLD Whole lung $(\mathrm{HU})$ & $-839.68(-856.24 \sim-817.42)$ & $-852.92(-871.94 \sim-835.07) *$ & $-857.25(-873.4 \sim-834.18) *$ & 0.005 \\
\hline MLD Right lung $(\mathrm{HU})$ & $-84 \mid .27(-856 .|4 \sim-8| 8.25)$ & $-855.27(-871.74 \sim-835.4) *$ & $-855.12(-873.67 \sim-834.98) *$ & 0.004 \\
\hline MLD Left lung $(H U)$ & $-838.08(-864.02 \sim-815.32)$ & $-852.12(-870.95 \sim-831.11)$ & $-858.67(-874.93 \sim-836.64) *$ & 0.005 \\
\hline $\mathrm{HI}$ Whole lung & $0.08 \pm 0.25$ & $0.14 \pm 0.28$ & $0.13 \pm 0.27$ & 0.398 \\
\hline $\mathrm{HI}$ Right lung & $0.08 \pm 0.29$ & $0.16 \pm 0.3$ & $0.17 \pm 0.29$ & 0.16 \\
\hline $\mathrm{HI}$ Left lung & $-0.1 \pm 0.29$ & $-0.09 \pm 0.28$ & $-0.12 \pm 0.32$ & 0.75 \\
\hline
\end{tabular}

Note: $* P<0.05$ compared with NS group.

Abbreviations: LC, lung capacity; \%LAA-950, the extent of emphysema of CT attenuation value below -950 HU; MED, mean emphysema density; MLD, mean lung density; $\mathrm{HI}$, emphysema heterogeneity index, when emphysema is equally distributed among the lobes or the full extent in the whole lung is $<\mathrm{I} \%, \mathrm{HI}$ is near zero; otherwise, $\mathrm{HI}=(\%$ LAA $\left.A_{\text {upper }}-\% \mathrm{LAA}_{\text {lower }}\right) /\left(\% \mathrm{LAA}_{\text {upper }}+\%\right.$ LAA lower $) * 100$.

\section{Analysis of the Relationship Between Smoking and EI}

Spearman's test was performed on 263 patients with smoking AECOPD. No correlation was observed between the frequency of smoking and \%LAA-950 Whole lung, $\mathrm{LC}_{\text {Whole lung, }} \mathrm{MED}$ whole lung, or $\mathrm{MLD}_{\text {whole lung. }}$

A model was established to elucidate the dependence of EI $>20 \%$ on smoking and other factors. Clinical practice and literature, ${ }^{9,10,13}$ outline the following factors which were included in the univariable logistic regression analysis: smoking (yes), age ( $>65$ years), FEV1\% ${ }_{\text {pred }}(<50 \%)$, BMI (<21), $\mathrm{PaO}_{2}(<60 \%), \mathrm{PaCO}_{2}(>50 \%), \mathrm{CAT}(>10)$, mMRC $(>2), \mathrm{KCO}$ $(<80 \%$ and $\geq 60 \%,<60 \%)$, complications (yes), and acute exacerbation hospitalization in the past 1 year (yes). A multicollinearity analysis was performed to ensure no collinearity among outcomes. The variance inflation factors (VIF) were 1.131 for age, 1.117 for smoking, 1.201 for the number of complications, 1.376 for acute exacerbation hospitalizations in the past 12 months, 1.117 for the CAT score, 1.435 for the mMRC score, 1.260 for BMI, 1.108 for WBC, 1.057 for $\mathrm{PaO} 2,1.330$ for $\mathrm{PaCO} 2,1.417$ for $\mathrm{FEV1 \%}{ }_{\mathrm{PRED}}$, and 1.343 for $\mathrm{DL}_{\mathrm{CO}} / \mathrm{VA}$ (KCO). The results indicate

A

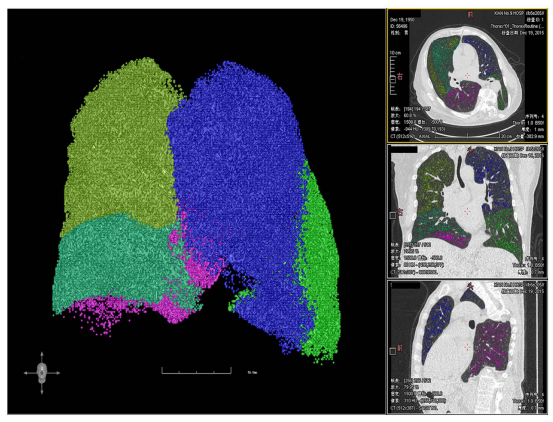

B

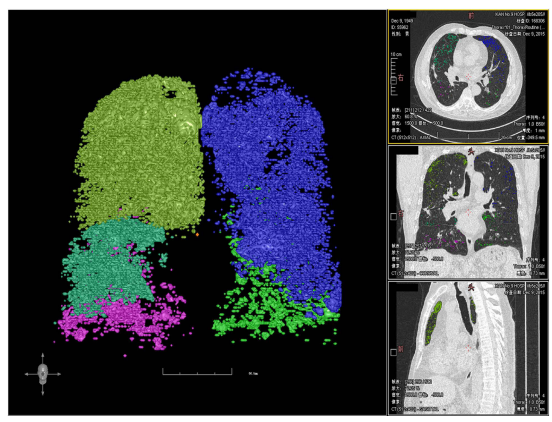

C

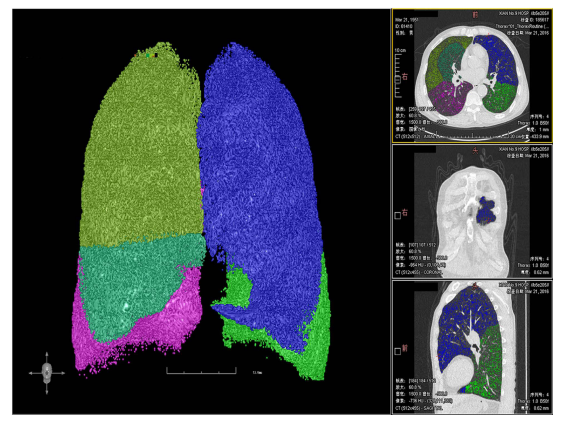

Figure 2 (A) A 65 years old male of NS: FEVI $=1.65 \mathrm{~L}$, FEVI/FVC=65.36\%, KCO=100.6\%, Z5\% pred $=99.7 \%, R_{5}=0.28, R_{20}=0.22, R_{5}-R_{20}=0.06, X_{5}=-0.1 I, F r e s=15.38, A x=0.49$, $E I=13.68 \%, M L D=-841.91 \mathrm{HU}, M E D=-979.35 \mathrm{HU}, \mathrm{LC}=4823 \mathrm{~mL}$. (B) $A$ 66 years old male of $F S: F E V I=0.92 \mathrm{~L}, \mathrm{FEVI} / \mathrm{FVC}=44.37 \%, \mathrm{KCO}=96.5 \%, Z 5 \%$ pred $=I 74.3 \%, R_{5}=0.46, R_{20}$ $=0.31, R_{5}-R_{20}=0.15, X_{5}=-0.27$, Fres $=20.07, A x=1.62$, El=26.85\%, MLD=-850.85HU, MED=-988.4HU, LC=6004mL. (C) A 65 years old male of CS: FEVI=I.16L, FEVI/ $\mathrm{FVC}=46.03 \%, \mathrm{KCO}=71.9 \%, \mathrm{Z} 5 \%_{\text {pred }}=242.5 \%, \mathrm{R}_{5}=0.64, \mathrm{R}_{20}=0.31, \mathrm{R}_{5}-\mathrm{R}_{20}=0.33, \mathrm{X}_{5}=-0.38$, Fres $=27.17, \mathrm{Ax}=3.63, \mathrm{El}=25.19 \%, \mathrm{MLD}=-874.26 \mathrm{HU}, \mathrm{MED}=-981.88 \mathrm{HU}$, $\mathrm{LC}=6905 \mathrm{~mL}$. 
Table 4 Logistic Regression Analysis of Smoking and EI

\begin{tabular}{|c|c|c|c|c|}
\hline \multirow[t]{2}{*}{ Characteristics } & \multicolumn{2}{|l|}{ Univariable Analysis } & \multicolumn{2}{|l|}{ Multivariable Analysis } \\
\hline & OR (95\% Cl) & $\mathbf{P}$ & OR (95\% Cl) & $\mathbf{P}$ \\
\hline Smoking & 4.185 (2.179 8.04) & $<0.001$ & $3.052(1.342 \sim 6.938)$ & 0.008 \\
\hline BMI, $\mathrm{kg} / \mathrm{m}^{2}$ & $3.448(1.967 \sim 6.044)$ & $<0.001$ & 2.429 (I.192 4.949) & 0.015 \\
\hline FEVI\%pred & $2.694(\mathrm{I} .63 \sim 4.45 \mathrm{I})$ & $<0.001$ & $1.954(1.014 \sim 3.765)$ & 0.045 \\
\hline $\mathrm{KCO}(60 \% \leq \mathrm{KCO}<80 \%)$ & $4.22(2.235 \sim 7.967)$ & $<0.001$ & $2.828(1.386 \sim 5.769)$ & 0.004 \\
\hline $\mathrm{KCO}(<60 \%)$ & $18.739(8.459 \sim 41.513)$ & $<0.001$ & $10.975(4.716 \sim 25.544)$ & $<0.001$ \\
\hline $\mathrm{PaCO}_{2}$ & $2.332(1.151 \sim 4.725)$ & 0.019 & & \\
\hline Comorbidities & $0.88(0.538 \sim 1.44)$ & 0.611 & & \\
\hline CAT & $0.967(0.596 \sim 1.572)$ & 0.894 & & \\
\hline Exacerbations/year & 1.181 (0.7|3 1.957) & 0.518 & & \\
\hline $\mathrm{mMRC}$ & $1.257(0.77 \sim 2.053)$ & $0.36 \mathrm{I}$ & & \\
\hline Age & 0.978 (0.60I I.59I) & 0.927 & & \\
\hline $\mathrm{PaO}_{2}$ & $1.116(0.574 \sim 2.17)$ & 0.747 & & \\
\hline
\end{tabular}

Notes: After adjusting age ( $>65$ years), FEVI\%pred ( $<50 \%)$, BMI $(<21)$, and DLCO/VA ( $<80 \%)$, the factor of smoking was related to emphysema formation El ( $\geq 20 \%)$.

that the VIF of all variables was $<5$, meaning that there is no collinearity among variables. Statistically different parameters were then included in multivariable logistic regression analysis, including smoking (yes), FEV1\% $\%_{\text {pred }}$ $(<50 \%)$, BMI $(<21), \mathrm{PaCO}_{2}(>50 \%)$, and $\mathrm{KCO}(<80 \%$ and $\geq 60 \%,<60 \%)$. The results showed a significant difference between smoking and EI after adjusting for other factors (Table 4). No difference was found in the 5-year survival rate between smokers and NS (Figure 3).

\section{Discussion}

COPD is a heterogeneous disease, and its occurrence in NS has not been widely recognized. Similarly, differences in characteristics of COPD in NS and smokers are not fully understood in part due to the scarcity of relevant clinical studies. Therefore, the purpose of this study was to identify the characteristics of AECOPD under different smoking exposures and assess 5-year survival among smoking status groups and provide more objective evidence of the etiological heterogeneity of AECOPD.

Differences were noted in gender, with males comprising 59\% NS while comprising $96.6 \%$ of the FS group and $98.1 \%$ of the CS group. The male sex is a recognized risk factor for COPD. ${ }^{3}$ The gender-related risk exposure status was different between smoking and non-smoking COPD. ${ }^{16}$ This phenomenon is widespread, particularly in developed and developing Asian countries, such as Japan and India, ${ }^{17}$ where most smokers are men, which is often related to social and cultural norms. The current study showed that NS was significantly older than the CS group, suggesting that smoking is more significant in the etiology of COPD than other non-smoking factors in China. Interestingly, an Indian study showed that biomass-COPD was comprised of younger than the smokers COPD group, ${ }^{17}$ while the Canadian Cohort of Obstructive Lung Disease study (CanCOLD) also showed that NS was younger and included more women. ${ }^{16}$

Reports on the proportion of non-smokers with COPD in the total COPD population are inconsistent with studies showing that non-smokers COPD accounted for 25-45\%. ${ }^{17,18}$ The COPDGene study reported that non-smoking COPD accounted for $27 \%$ of all COPD patients. ${ }^{9,19}$ In this study, NS accounted for $23 \%$ of the total AECOPD. Regardless of whether smoking is involved or not, the AECOPD did not differ in assessing the key indicators of the disease, such as CAT, mMRC, BMI, and the history of acute exacerbations in the past 12 months. This study found that all smokers (CS and FS) had a significantly lower ratio of carbon monoxide diffusion to alveolar ventilation $\left(\mathrm{DL}_{\mathrm{CO}} / \mathrm{VC}\right.$ or $\mathrm{KCO}$ ) than NS. This suggests that lung diffusion dysfunction (oxygen translation problems from the alveolar membrane into the blood) in the smokers was more obvious, inferring that lung parenchymal damage such as alveolar tissue was more serious. Similar results were reported in the CanCOLD study in the COPD stable population, where results showed that smoking COPD was significantly lower in $\mathrm{DL}_{\mathrm{CO}} / \mathrm{VA}$ than that in non-smoking COPD. ${ }^{16}$ 


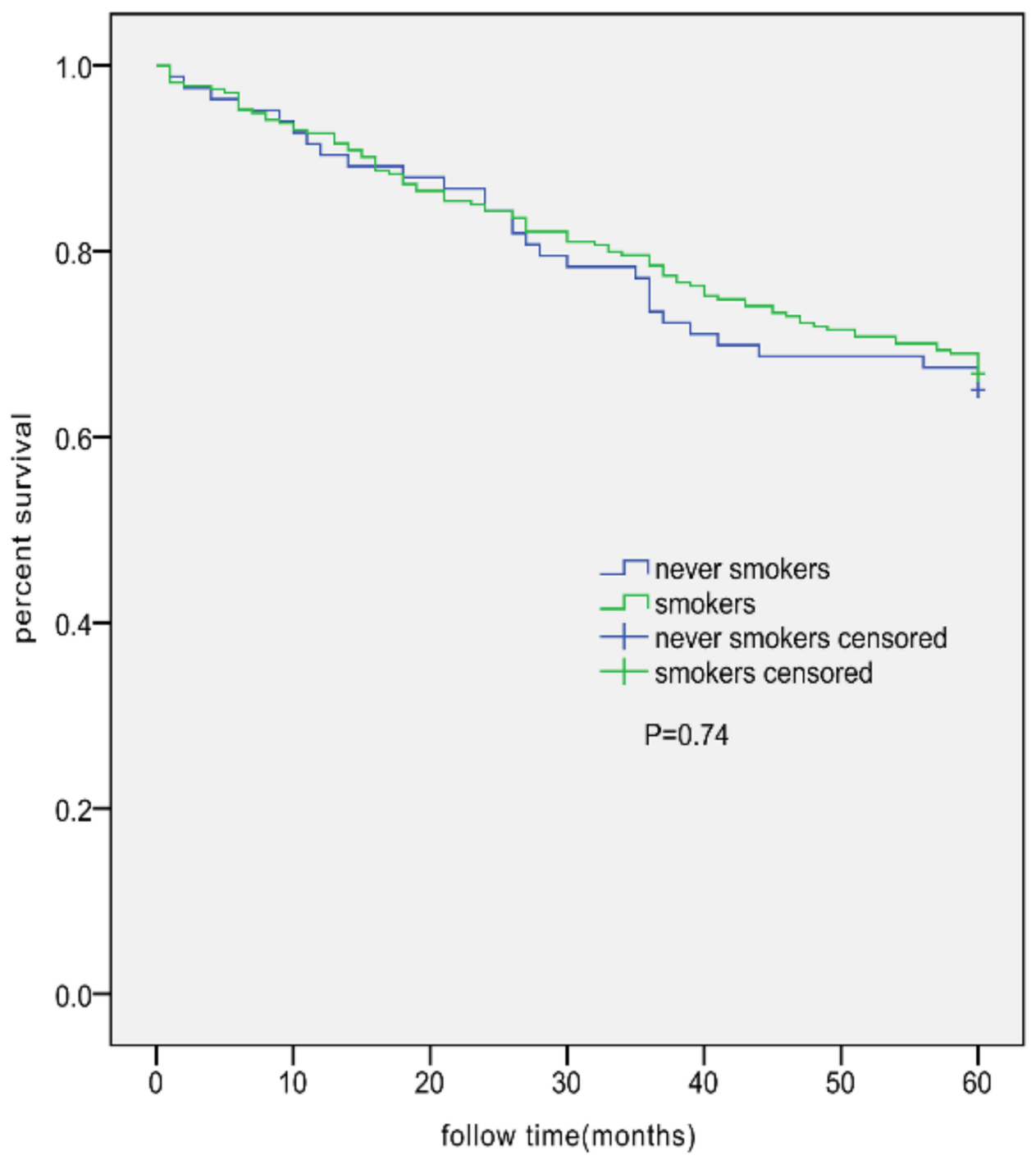

Figure 3 Kaplan-Meier survival curves for AECOPD patients in the NS group ( $n=83 ; 29$ deaths) and all smokers AECOPD group ( $n=274 ; 91$ deaths). No significant difference between the two groups was observed (log rank test, $0.113 ; \mathrm{P}=0.74$ ).

Although the current diagnosis and evaluation of COPD are mainly based on symptoms, frequency of exacerbations, and lung function, chest CT scans can provide a wealth of information related to diagnosis and individualized treatment. ${ }^{9}$ Therefore, finding reliable imaging markers is vital in COPD research. Quantitative CT measurement of EI was a more accepted imaging parameter and a clear predictor of COPD, given its reflection of both pathological and functional impairments. ${ }^{20,21}$ The COPDGene study found that for COPD with an EI of 35\%, an additional increase in EI of $5 \%$ would increase the COPD deterioration rate 1.18 times. ${ }^{19}$ In this study, a CT scan revealed that smokers had more extensive and severe emphysema than NS. Like the pulmonary function index $\mathrm{DL}_{\mathrm{CO}} / \mathrm{VA}$ mentioned above, this suggests lung parenchymal damage from a pathophysiological point, while EI also means severer lung parenchymal and lung diffusion damage from a pathological point of view. Similarly, other imaging parameters such as MED, MLD, and LC reflected the same pathological changes and clinical significance. This study showed that smoking was a risk factor for emphysema $(\mathrm{EI}=20 \%)$, which is consistent with other studies that have recognized that smoking can damage lung parenchymal tissues through mechanisms including inflammation, oxidative stress, and elevated protease activity. ${ }^{22}$ The inflammatory process involves numerous cells such as macrophages, neutrophils, different subgroups of $\mathrm{T}$ and B lymphocytes, and dendritic cells. Research between smoking and the autoimmune origin of COPD is also 
attracting more interest, opening new research prospects for both the cause of COPD and new potential targets for treatment.

Emphysema is one of the hallmark imaging features of COPD. Only $40 \%$ of smokers would develop COPD, and it was found that genetic susceptibility may be involved in the occurrence of COPD. ${ }^{22}$ Therefore, the relationship between smoking and emphysema is not a simple linear relationship. ${ }^{23}$ Similarly, in this study, no correlations were found between the amount of smoking (pack-years) and the EI, supporting the above viewpoints and reflecting the heterogeneity and complexity of COPD pathogenesis.

Airway wall thickening is a result of inflammatory changes and airway remodeling. ${ }^{24,25}$ More accurate and reliable airway imaging markers might provide vital information for early diagnosis and evaluation of COPD. The COPDGene early study showed that a thickening of the bronchus by $1 \mathrm{~mm}$, led to an acute exacerbation rate of COPD increasing 1.84 times per year. ${ }^{19}$ In this study, there were no differences in airway measurements expressed as WA\% of a specific segment and sub-segment bronchus between the smoker and NS groups, which might be due to the method for determining thickness not being sensitive enough and the measured bronchial levels concentrated in larger airways, which could not fully reflect the thickening of the small airway wall. In another study, a Pil0 was used (expressed as the square root of the wall area of a hypothetical airway with an internal perimeter of $10 \mathrm{~mm}$ ) to measure 2000 smokers and 46 NS who were followed for 5 years; the results found that Pil0 decreased in the FS subjects and increased in subjects that began smoking again. ${ }^{24}$

Interestingly, it was observed that the IOS parameters $\mathrm{R}_{5}, \mathrm{R}_{20}, \mathrm{R}_{5}-\mathrm{R}_{20}, \mathrm{X}_{5}$, Fres, and Ax were significantly higher in the NS compared with smokers, indicating that the NS showed higher resistance and blockage in the central and peripheral airway and implying this group might require more diastolic airway treatment. Previous studies have also found that IOS parameters have a certain correlation with traditional lung function parameters with complementary value for assessing pathophysiological changes of COPD. ${ }^{12}$ This study showed that NS displayed more obvious characteristics of airway obstruction, which comport with similar conclusions of an Indian study that showed that $R_{5}, A x$, and resonant frequency values were significantly greater in NS than smoking, but no differences were found in $\mathrm{R}_{5}-\mathrm{R}_{20}, \mathrm{R}_{5}-\mathrm{R}_{20} / \mathrm{R}_{5}$ and $\mathrm{X}_{5}$ between the groups. ${ }^{17} \mathrm{In}$ order to assess differences between the two studies, the present study focused on the exacerbation of COPD, in which more mucosal edema and inflammatory cell infiltration are observed, leading to more obvious airway obstruction. Therefore, IOS parameters possess certain application values in AECOPD, superior to airway obstruction.

This study implies that NS suffer from the "airway predominant phenotype" more than smokers. These observations provide insights into phenotypic differences in potential pathogenic factors. This study looking at differences in clinical subtypes under different exposure factors is valuable in providing clinicians with better evidence for treatment decisions. Hence, smoking was a risk factor for emphysema in AECOPD. Similarly, FEV1\% $\%_{\text {red }}<50 \%$, BMI $<21$, KCO $(60 \% \leq \mathrm{KCO}<80 \%)$ were also independent risk factors. Therefore, when taken together, the results suggest that AECOPD is not worse in NS and smokers since the survival outcome was similar among the groups since COPD with pathologic changes involving airway and emphysema have high morbidity and mortality. ${ }^{3}$ On the other hand, NS and smokers have different etiologies of AECOPD, suggesting that NS and smokers with AECOPD could benefit from different therapeutic approaches. Studies and trials should be designed to examine such therapies.

The present study had some limitations. It was not a longitudinal or a multicenter study. Due to the nature of the retrospective study of the current study, there may be information bias, and a large sample size prospective study is needed for further verification. Despite that, we present one of the few studies on the etiological heterogeneity of the AECOPD, with its value being for the different populations and ethnic groups, which resulted in similar findings in different periods.

\section{Conclusion}

This study revealed heterogeneity among patients with AECOPD regarding the pathogenic risk factors. The results suggest that the lung diffusion dysfunction (oxygen diffusion problems through the alveolar membrane) in the smokers was more obvious, inferring that lung parenchymal damage such as alveolar tissue was more serious than in NS. On the other hand, AECOPD in NS appeared to involve airway resistance more than alveolar damage. IOS had application value in airway dominant AECOPD with no difference in 5-year survival being uncovered. 


\section{Abbreviations}

AECOPD, acute exacerbation of chronic obstructive pulmonary disease; NS, never smoked; FS, former smokers; CS, current smokers; COPD, chronic obstructive pulmonary disease; CT, computed tomography; GOLD, Global Initiative for Obstructive Lung Disease; BMI, body mass index; WBC, white blood cell count; CRP, C-reactive protein; PCT, procalcitonin; CAT, COPD Assessment Test; MED, mean emphysema density; MLD, mean lung density; LC, lung capacity; HI, heterogeneity index.

\section{Data Sharing Statement}

The datasets used and/or analyzed during the current study are available from the corresponding author on reasonable request.

\section{Ethics Approval and Informed Consent}

This work has been carried out in accordance with the Declaration of Helsinki (2000) of the World Medical Association. This study was approved by the ethics committee of Xi'an Ninth hospital (\#014001). The data used in the study did not involve information that can be used to identify the patients. The use of the patient data will not adversely affect patients. All data were collected from the medical charts. No new tests or measurements were performed. The patients were not contacted to obtain new data. Therefore, due to the retrospective nature of this study, informed consent of patients was waived.

\section{Acknowledgments}

We thank our generous funders, which undergirded this research. The funders had no role in the study design, data collection and analysis, decision to publish, or manuscript preparation.

\section{Author Contributions}

All authors made a significant contribution to the work reported, whether that is in the conception, study design, execution, acquisition of data, analysis and interpretation, or in all these areas; took part in drafting, revising or critically reviewing the article; gave final approval of the version to be published; have agreed on the journal to which the article has been submitted; and agree to be accountable for all aspects of the work.

\section{Funding}

This research was supported by the Social Development Science Research Project of Shaanxi Province (No. 2016SF151) and the Xi'an Science and Technology Projects (No. 2016045SF/YX01 and No. XA2020-YXYJ-0026).

\section{Disclosure}

The authors report no conflicts of interest in this work.

\section{References}

1. Murphy SL, Xu J, Kochanek KD. Deaths: final data for 2010. Natl Vital Stat Rep. 2013;61(4):1-117

2. GBD 2016 Causes of Death Collaborators. Global, regional, and national age-sex specific mortality for 264 causes of death, 1980-2016: a systematic analysis for the Global Burden of Disease Study 2016. Lancet 2017;390(10100):1151-1210. doi:10.1016/S0140-6736(17)32152-9

3. Vogelmeier CF, Criner GJ, Martinez FJ, et al. Global Strategy for the Diagnosis, Management, and Prevention of Chronic Obstructive Lung Disease 2017 Report. GOLD Executive Summary. Am J Respir Crit Care Med. 2017;195(5):557-582. doi:10.1164/rccm.201701-0218PP

4. Qaseem A, Wilt TJ, Weinberger SE, et al. Diagnosis and management of stable chronic obstructive pulmonary disease: a clinical practice guideline update from the American College of Physicians, American College of Chest Physicians, American Thoracic Society, and European Respiratory Society. Ann Intern Med. 2011;155(3):179-191. doi:10.7326/0003-4819-155-3-201108020-00008

5. Labaki WW, Han MK. Improving detection of early chronic obstructive pulmonary disease. Ann Am Thorac Soc. 2018;15(Supplement_4):S243S248. doi:10.1513/AnnalsATS.201808-529MG

6. Yan Y, Yi N, Mengwu T, et al. Major finding of 2015 China adults tobacco survery. Chin J Health Manage. 2016;10(2):85-87. doi:10.3760/cma.j. issn.1674-0815.2016.02.002

7. Wang C, Xu J, Yang L, et al. Prevalence and risk factors of chronic obstructive pulmonary disease in China (the China Pulmonary Health CPH study): a national cross-sectional study. Lancet. 2018;391(10131):1706-1717. doi:10.1016/S0140-6736(18)30841-9 
8. Chronic Obstructive Pulmonary Disease Group of Chinese Thoracic S, Chronic Obstructive Pulmonary Disease Committee of Chinese Association of Chest P. Guidelines for the diagnosis and management of chronic obstructive pulmonary disease (revised version 2021). Chin J Tuberc Respir Dis. 2021;44(3):170-205. doi:10.3760/cma.j.cn112147-20210109-00031

9. Maselli DJ, Bhatt SP, Anzueto A, et al. Clinical epidemiology of COPD. Chest. 2019;156(2):228-238. doi:10.1016/j.chest.2019.04.135

10. Wei X, Yu N, Ding Q, et al. The features of AECOPD with carbon dioxide retention. BMC Pulm Med. 2018;18(1):124. doi:10.1186/s12890-0180691-8

11. Wei X, Ding Q, Yu N, et al. Imaging features of chronic bronchitis with Preserved Ratio and Impaired Spirometry (PRISm). Lung. 2018;196 (6):649-658. doi:10.1007/s00408-018-0162-2

12. Wei X, Shi Z, Cui Y, et al. Impulse oscillometry system as an alternative diagnostic method for chronic obstructive pulmonary disease. Medicine. 2017;96(46):e8543. doi:10.1097/MD.0000000000008543

13. Wei X, Ma Z, Yu N, et al. Risk factors predict frequent hospitalization in patients with acute exacerbation of COPD. Int J Chron Obstruct Pulmon Dis. 2018;13:121-129. doi:10.2147/COPD.S152826

14. Yu N, Wei X, Li Y,et al. Computed tomography quantification of pulmonary vessels in chronic obstructive pulmonary disease as identified by $3 \mathrm{D}$ automated approach. Medicine. 2016;95(40):e5095. doi:10.1097/MD.0000000000005095

15. Bourbeau J, Tan WC, Benedetti A, et al. Canadian Cohort Obstructive Lung Disease (CanCOLD): fulfilling the need for longitudinal observational studies in COPD. COPD. 2014;11(2):125-132. doi:10.3109/15412555.2012.665520

16. Tan WC, Sin DD, Bourbeau J, et al. Characteristics of COPD in never-smokers and ever-smokers in the general population: results from the CanCOLD study. Thorax. 2015;70(9):822-829. doi:10.1136/thoraxjnl-2015-206938

17. Salvi SS, Brashier BB, Londhe J, et al. Phenotypic comparison between smoking and non-smoking chronic obstructive pulmonary disease. Respir Res. 2020;21(1). doi:10.1186/s12931-020-1310-9

18. Salvi SS, Barnes PJ. Chronic obstructive pulmonary disease in non-smokers. Lancet. 2009;374:733-743. doi:10.1016/S0140-6736(09)61303-9

19. Han MK, Kazerooni EA, Lynch DA, et al. Chronic obstructive pulmonary disease exacerbations in the COPDGene study: associated radiologic phenotypes. Radiology. 2011;261(1):274-282. doi:10.1148/radiol.11110173

20. Mohamed Hoesein FA, de Hoop B, Zanen P, et al. CT-quantified emphysema in male heavy smokers: association with lung function decline. Thorax. 2011;66(9):782-787. doi:10.1136/thx.2010.145995

21. Xie M, Wang W, Dou S,et al. Quantitative computed tomography measurements of emphysema for diagnosing asthma-chronic obstructive pulmonary disease overlap syndrome. Int J Chron Obstruct Pulmon Dis. 2016;11:953-961. doi:10.2147/COPD.S104484

22. Corlăţeanu A, Odajiu I, Botnaru V,et al. From smoking to COPD-current approaches. Pneumologia. 2016;65(1):20-23.

23. Silverman EK, Vestbo J, Agusti A, et al. Opportunities and challenges in the genetics of COPD 2010: an International COPD Genetics Conference report. COPD. 2011;8(2):121-135. doi:10.3109/15412555.2011.558864

24. Charbonnier JP, Pompe E, Moore C, et al. Airway wall thickening on CT: relation to smoking status and severity of COPD. Respir Med. 2019;146:36-41.doi:10.1016/j.rmed.2018.11.014

25. James AL, Wenzel S. Clinical relevance of airway remodelling in airway diseases. Eur Respir J. 2007;30(1):134-155. doi:10.1183/ 09031936.00146905

International Journal of Chronic Obstructive Pulmonary Disease

Dovepress

\section{Publish your work in this journal}

The International Journal of COPD is an international, peer-reviewed journal of therapeutics and pharmacology focusing on concise rapid reporting of clinical studies and reviews in COPD. Special focus is given to the pathophysiological processes underlying the disease, intervention programs, patient focused education, and self management protocols. This journal is indexed on PubMed Central, MedLine and CAS. The manuscript management system is completely online and includes a very quick and fair peer-review system, which is all easy to use. Visit http://www. dovepress.com/testimonials.php to read real quotes from published authors.

Submit your manuscript here: https://www.dovepress.com/international-journal-of-chronic-obstructive-pulmonary-disease-journal 